\title{
Barrier-Engineered Arsenide-Antimonide Heterojunction Tunnel FETs With Enhanced Drive Current
}

\author{
Dheeraj Mohata, Student Member, IEEE, Bijesh Rajamohanan, Student Member, IEEE, \\ Theresa Mayer, Senior Member, IEEE, Mantu Hudait, Senior Member, IEEE, Joel Fastenau, Member, IEEE, \\ Dmitri Lubyshev, Amy W. K. Liu, Senior Member, IEEE, and Suman Datta, Senior Member, IEEE
}

\begin{abstract}
In this letter, we experimentally demonstrate enhancement in drive current $I_{\mathrm{ON}}$ and reduction in drain-induced barrier thinning (DIBT) in arsenide-antimonide staggered-gap heterojunction (hetj) tunnel field-effect transistors (TFETs) by engineering the effective tunneling barrier height $\mathbf{E b}_{\text {eff }}$ from 0.58 to $0.25 \mathrm{eV}$. Moderate-stagger $\mathrm{GaAs}_{0.4} \mathrm{Sb}_{0.6} / \mathbf{I n}_{0.65} \mathbf{G a}_{0.35} \mathrm{As}$ $\left(\mathrm{Eb}_{\mathrm{eff}}=0.31 \mathrm{eV}\right)$ and high-stagger $\mathrm{GaAs}_{0.35} \mathrm{Sb}_{0.65} /$ $\mathrm{In}_{0.7} \mathrm{Ga}_{0.3} \mathrm{As}\left(\mathrm{Eb}_{\mathrm{eff}}=0.25 \mathrm{eV}\right)$ hetj TFETs are fabricated, and their electrical results are compared with the $\operatorname{In}_{0.7} \mathbf{G a}_{0.3} \mathrm{As}$ homojunction (homj) TFET $\left(\mathrm{Eb}_{\mathrm{eff}}=0.58 \mathrm{eV}\right)$. Due to the $57 \%$ reduction in $\mathrm{Eb}_{\text {eff }}$, the $\mathrm{GaAs}_{0.35} \mathrm{Sb}_{0.65} / \mathrm{In}_{0.7} \mathrm{Ga}_{0.3}$ As hetj TFET achieves $253 \%$ enhancement in $I_{\mathrm{ON}}$ over the $\mathrm{In}_{0.7} \mathrm{Ga}_{0.3} \mathrm{As}$ homj TFET at $V_{D S}=0.5 \mathrm{~V}$ and $V_{G S}-V_{\text {OFF }}=1.5 \mathrm{~V}$. With electrical oxide thickness (Toxe) scaling from 2.3 to $2 \mathrm{~nm}$, the enhancement further increases to $350 \%$, resulting in a record high $I_{\mathrm{ON}}$ of $135 \mu \mathrm{A} / \mu \mathrm{m}$ and $65 \%$ reduction in DIBT at $V_{D S}=0.5 \mathrm{~V}$.
\end{abstract}

Index Terms-GaAsSb, InGaAs, stagger, tunnel field-effect transistors (TFETs).

\section{INTRODUCTION}

I NTERBAND tunnel field-effect transistors (TFETs) are being extensively explored as a low $V_{\mathrm{CC}}(0.5 \mathrm{~V}$ and below $)$ logic switch owing to their ability to show sub- $k T / q$ steep switching [1]-[4]. A point switching slope (SS) less than $60 \mathrm{mV} / \mathrm{dec}$ has been already demonstrated at room temperature [1], [2]. However, the drive current $I_{\mathrm{ON}}$ demonstrated to date are significantly lower than the metal-oxide-semiconductor field-effect transistors (MOSFETs) mainly due to the large source-side effective tunneling barrier height $\mathrm{Eb}_{\text {eff }}$ [1]-[3].

Mixed arsenide-antimonide-based lattice-matched heterojunctions $\left(\mathrm{GaAs}_{x} \mathrm{Sb}_{1-x} / \mathrm{In}_{y} \mathrm{Ga}_{1-y} \mathrm{As}\right)$ provide a wide range of compositionally tunable $\mathrm{Eb}_{\mathrm{eff}}$ [5]. With increasing $\mathrm{Sb}$ and In

Manuscript received May 30, 2012; revised July 31, 2012; accepted August 7, 2012. Date of publication September 27, 2012; date of current version October 19, 2012. This work was supported in part by the Nanoelectronics Research Initiative through the Midwest Institute for Nanoelectronics Discovery and Intel Corporation. The review of this letter was arranged by Editor J. Cai.

D. Mohata, B. Rajamohanan, T. Mayer, and S. Datta are with the Department of Electrical Engineering, The Pennsylvania State University, University Park, PA 16802 USA (e-mail: dkm154@psu.edu).

M. Hudait is with the Department of Electrical and Computer Engineering, Virginia Polytechnic Institute and State University, Blacksburg, VA 24061 USA.

J. Fastenau, D. Lubyshev, and A. W. K. Liu are with IQE, Inc., Bethlehem, PA 18015 USA.

Color versions of one or more of the figures in this letter are available online at http://ieeexplore.iee.org.

Digital Object Identifier 10.1109/LED.2012.2213333
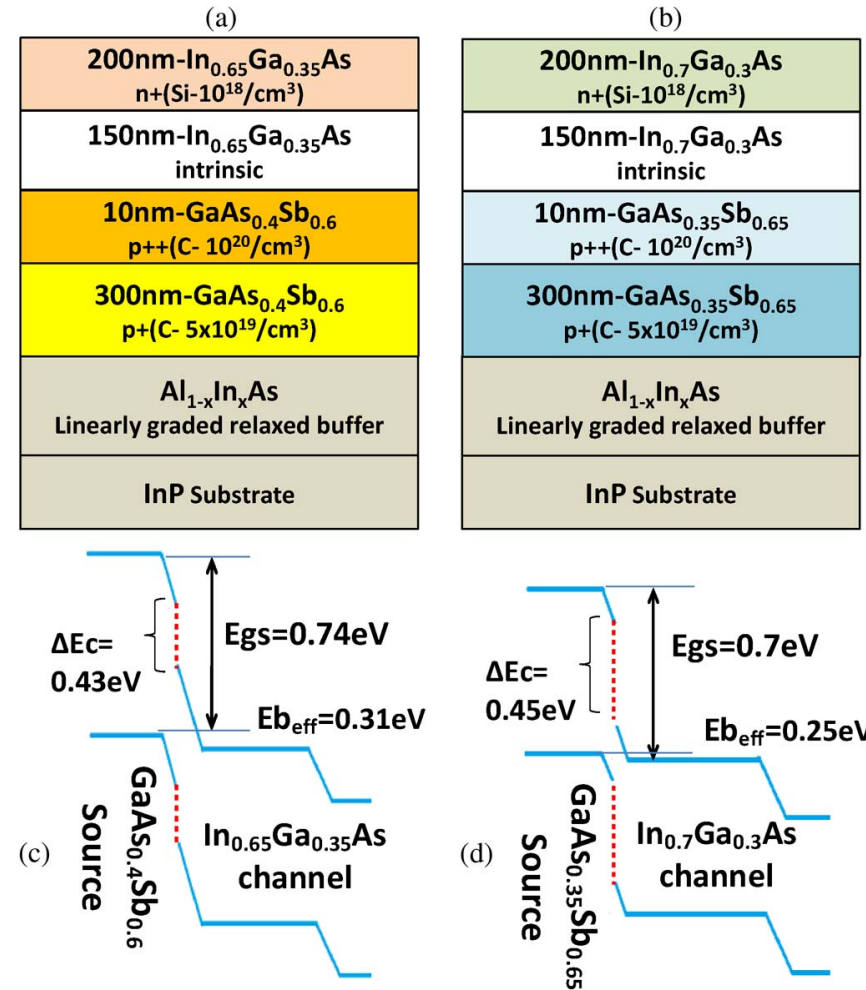

Fig. 1. (a) and (b) Cross-sectional schematics of (a) the $\mathrm{GaAs}_{0.4} \mathrm{Sb}_{0.6} /$ $\mathrm{In}_{0.65} \mathrm{Ga}_{0.35} \mathrm{As}$ moderate hetj and (b) the $\mathrm{GaAs}_{0.35} \mathrm{Sb}_{0.65} / \mathrm{In}_{0.7} \mathrm{Ga}_{0.3} \mathrm{As}$ high hetj TFET layer structures. (c) and (d) Energy band diagrams showing the band alignment at the moderate- and high-stagger S-C heterointerface.

compositions, $\mathrm{Eb}_{\text {eff }}$ can be reduced from $0.5 \mathrm{eV}(x=0.5, y=$ $0.53)$ to $0 \mathrm{eV}(x=0.1, y=1)$, and hence, the TFET $I_{\mathrm{ON}}$ can approach the MOSFET level without compromising the steep switching and high $I_{\mathrm{ON}} / I_{\mathrm{OFF}}$ property desirable in a lowpower logic switch.

In this letter, we demonstrate n-channel moderate-stagger $\mathrm{GaAs}_{0.4} \mathrm{Sb}_{0.6} / \mathrm{In}_{0.65} \mathrm{Ga}_{0.35} \mathrm{As} \quad\left(\mathrm{Eb}_{\mathrm{eff}}=0.31 \mathrm{eV}\right)$ and highstagger $\mathrm{GaAs}_{0.35} \mathrm{Sb}_{0.65} / \mathrm{In}_{0.7} \mathrm{Ga}_{0.3} \mathrm{As}\left(\mathrm{Eb}_{\text {eff }}=0.25 \mathrm{eV}\right)$ heterojunction (hetj) TFETs and compare their electrical results with the $\mathrm{In}_{0.7} \mathrm{Ga}_{0.3}$ As homojunction (homj) TFET $\left(\mathrm{Eb}_{\mathrm{eff}}=\right.$ $0.58 \mathrm{eV}$ ). By scaling $\mathrm{Eb}_{\text {eff }}$ from 0.58 to $0.25 \mathrm{eV}$, with the electrical oxide thickness (Toxe) being $2.3 \mathrm{~nm}$, we demonstrate $253 \%$ enhancement in drive current at $V_{D S}=0.5 \mathrm{~V}$ and $V_{G S}-$ $V_{\mathrm{OFF}}=1.5 \mathrm{~V}, V_{\mathrm{OFF}}$ being the gate voltage corresponding to $I_{\mathrm{OFF}}=5 \mathrm{nA} / \mu \mathrm{m}$. By further scaling Toxe to $2 \mathrm{~nm}$, the enhancement in drive current is further shown to increase to 
(a)
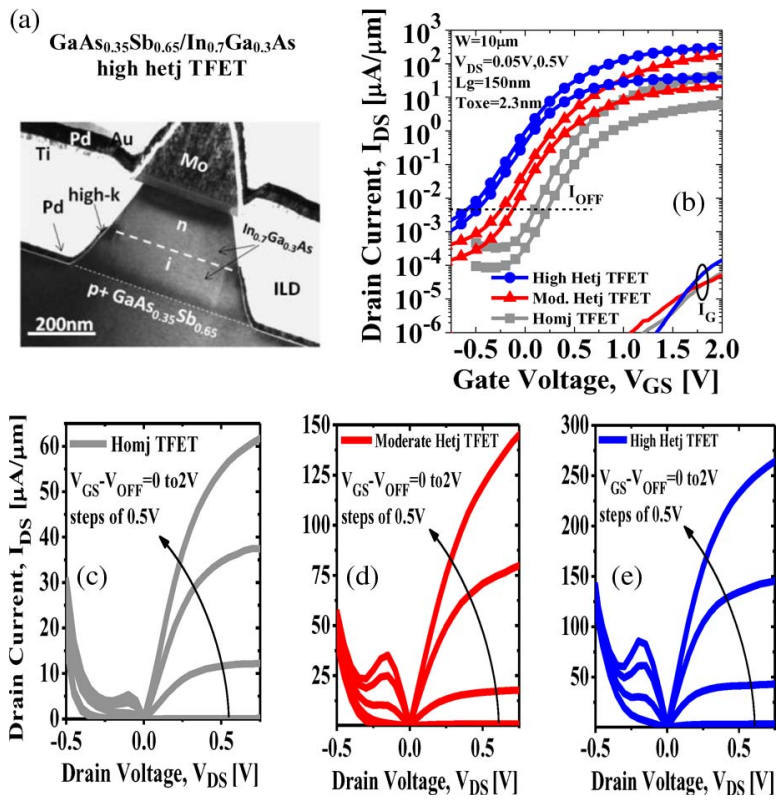

Fig. 2. (a) Cross-sectional TEM image of the fabricated nanopillar high hetj TFET device. (b) Measured room temperature transfer characteristics $\left(I_{D S}-V_{G S}\right)$ of the $\operatorname{In}_{0.7} \mathrm{Ga}_{0.3}$ As homj TFET $\left(\mathrm{Eb}_{\text {eff }}=0.58 \mathrm{eV}\right)$, $\mathrm{GaAs}_{0.4} \mathrm{Sb}_{0.6} / \mathrm{In}_{0.65} \mathrm{Ga}_{0.35} \mathrm{As}$ moderate hetj TFET $\left(\mathrm{Eb}_{\mathrm{eff}}=0.31 \mathrm{eV}\right)$, and $\mathrm{GaAs}_{0.35} \mathrm{Sb}_{0.65} / \mathrm{In}_{0.7} \mathrm{Ga}_{0.3} \mathrm{As}$ high hetj TFET $\left(\mathrm{Eb}_{\mathrm{eff}}=0.25 \mathrm{eV}\right)$. (c)-(e) Measured output characteristics $\left(I_{D S}-V_{D S}\right)$ of the fabricated devices. $I_{\mathrm{ON}}$ increases by $253 \%$ due to a decrease in $\mathrm{Eb}_{\text {eff }}$ from 0.58 to $0.25 \mathrm{eV}$.

$350 \%$, exhibiting a record high $I_{\mathrm{ON}}$ of $135 \mu \mathrm{A} / \mu \mathrm{m}$. Draininduced barrier thinning (DIBT) is shown to reduce by $65 \%$ at $V_{D S}=0.5 \mathrm{~V}$.

Section II describes the layer structure and device fabrication details; Section III discusses electrical results and benchmarks $I_{\mathrm{ON}}$ and $I_{\mathrm{ON}} / I_{\mathrm{OFF}}$; Section IV concludes this letter.

\section{LAYER STRUCtURES AND DEVICE FABRicATION}

$\mathrm{In}_{0.7} \mathrm{Ga}_{0.3} \mathrm{As}$ homj control and $\mathrm{GaAs}_{1-x} \mathrm{Sb}_{x} / \mathrm{In}_{y} \mathrm{Ga}_{1-y} \mathrm{As}$ hetj TFETs with moderate $(x=0.6, y=0.65)$ and high $(x=$ $0.65, y=0.7)$ stagger were grown on a semi-insulating $\operatorname{InP}$ substrate using solid-source molecular beam epitaxy. Fig. 1(a) and (b) shows the schematic layer structures for the hetj TFETs. The channel material consists of $150 \mathrm{~nm}$ of intrinsically doped $\operatorname{In}_{0.7} \mathrm{Ga}_{0.3}$ As for the high hetj TFET and $150 \mathrm{~nm}$ of $\mathrm{In}_{0.65} \mathrm{Ga}_{0.35}$ As for the moderate hetj TFET. The layer structure for the $\mathrm{In}_{0.7} \mathrm{Ga}_{0.3}$ As homj TFET is essentially the same as the high hetj TFET, except that the $\mathrm{GaAs}_{0.35} \mathrm{Sb}_{65}$ source region is replaced by $\mathrm{In}_{0.7} \mathrm{Ga}_{0.3}$ As. Fig. 1(c) and (d) shows the energy band diagrams explaining the band alignment for the moderate and high hetj TFETs at the staggered source-channel (S-C) interface. $\mathrm{Eb}_{\text {eff }}$ is approximately given by $E_{g s}-\Delta E_{C}$, where $E_{g s}$ is the band gap of the source, and $\Delta E_{C}$ represents the conduction band discontinuity [6].

Fig. 2(a) shows the cross-sectional transmission electron microscopy (TEM) image of the fabricated vertical nanopillar high hetj TFET device. The detailed nanopillar TFET fabrication process flow can be referred in [7]. The high- $k$ stack consists of 1-nm $\mathrm{Al}_{2} \mathrm{O}_{3} / 3.5-\mathrm{nm} \mathrm{HfO}_{2}($ Toxe $=2.3 \mathrm{~nm})$ grown by an atomic layer deposition technique at $250{ }^{\circ} \mathrm{C}$. The gate metal on the pillar sidewall consists of 20-nm electron-beam evaporated Pd.
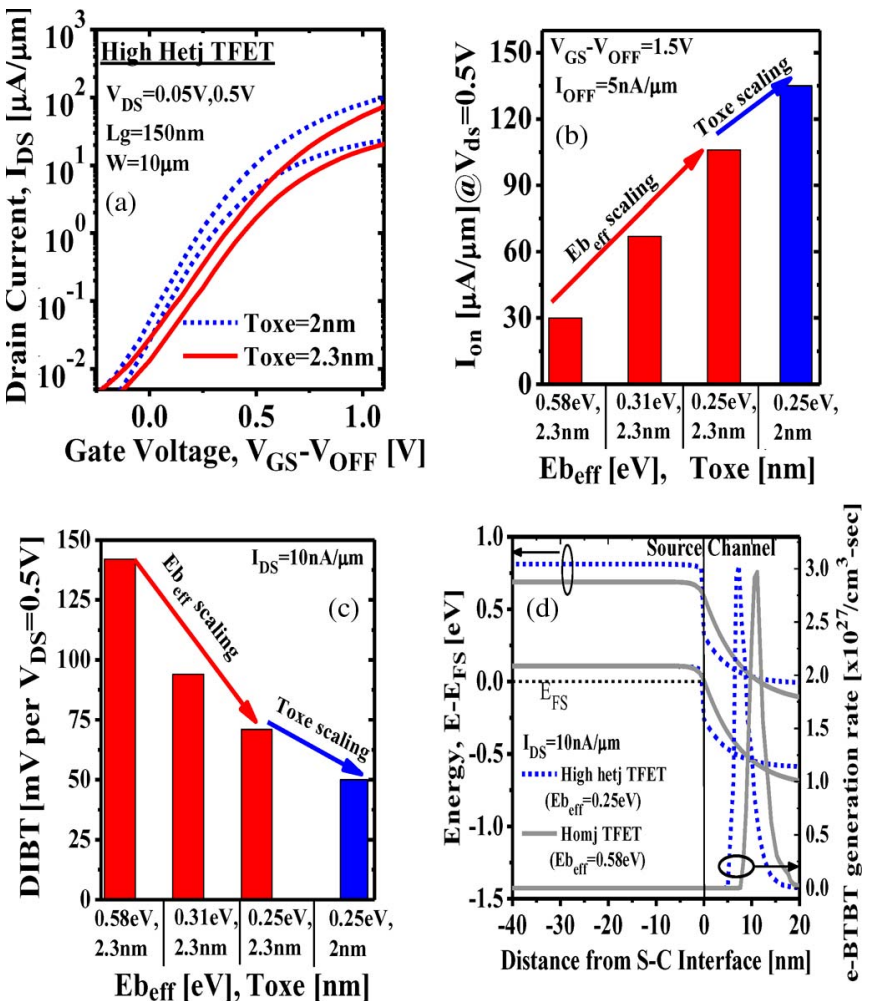

Fig. 3. (a) Reduction in the SS of the $I_{D S}-V_{G S}$ of the high hetj TFET due to scaling of Toxe from 2.3 to $2 \mathrm{~nm}$. (b) and (c) Histograms summarizing enhancement in $I_{\mathrm{ON}}$ and reduction in DIBT by scaling Eb $b_{\text {eff }}$ and Toxe. (d) Simulations showing the comparison of electron band-to-band tunneling (e-BTBT) generation profiles between the homj and high hetj TFETs at $10 \mathrm{nA} / \mu \mathrm{m}$, $V_{D S}=0.5 \mathrm{~V}$ [8]. With reducing $\mathrm{Eb}_{\text {eff }}$ due to increasing stagger, BTBT generation occurs closer to the metallurgical S-C interface.

\section{Electrical Results AND BENChMARKING}

Fig. 2(b) shows room temperature transfer characteristics $\left(I_{D S}-V_{G S}\right)$ of the homj TFET and moderate and high hetj TFET devices measured at $V_{D S}=0.05$ and $0.5 \mathrm{~V}$. It can be observed that turnoff voltage $V_{\mathrm{OFF}}$ shifts left with reducing $\mathrm{Eb}_{\text {eff }}$. This is expected since, with higher $\Delta E_{C}$ and a lower $E b_{\text {eff }}$, the same tunneling current can be achieved at a lower applied gate bias. At $I_{\mathrm{OFF}}=5 \mathrm{nA} / \mu \mathrm{m}, V_{D S}=0.5 \mathrm{~V}, V_{G S}-V_{\mathrm{OFF}}=$ $1.5 \mathrm{~V}$, and Toxe $=2.3 \mathrm{~nm}$, the high hetj TFET exhibits $I_{\mathrm{ON}}=$ $106 \mu \mathrm{A} / \mu \mathrm{m}$, which shows that band-gap engineering can fundamentally mitigate the drive current limitation in TFETs. Fig. 2(c)-(e) shows the room temperature output characteristics $\left(I_{D S}-V_{D S}\right)$ for the different TFET devices. All devices show clear signature of output drain-current saturation. The negative differential resistance behavior observed for negative $V_{D S}$ is a characteristic behavior of an Esaki tunneling junction.

Fig. 3(a) compares $I_{D S}-V_{G S}$ of the high hetj TFET device with Toxe $=2$ and $2.3 \mathrm{~nm}$. Fig. 3(b) summarizes the enhancement in $I_{\mathrm{ON}}$ as a result of $\mathrm{Eb}_{\mathrm{eff}}$ and Toxe scaling. With Toxe being $2.3 \mathrm{~nm}$ and $\mathrm{Eb}_{\text {eff }}$ scaled from $0.58 \mathrm{eV}$ (homj TFET) to $0.31 \mathrm{eV}$ (moderate hetj TFET), the $I_{\mathrm{ON}}$ at $V_{D S}=0.5 \mathrm{~V}$ and $V_{G S}-V_{\mathrm{OFF}}=1.5 \mathrm{~V}$ increases by $123 \%$. With further reduction in $\mathrm{Eb}_{\text {eff }}$ to $0.25 \mathrm{eV}$ (high hetj TFET), the enhancement increases to $253 \%$ primarily due to increased tunneling transmission efficiency. By scaling Toxe to $2 \mathrm{~nm}$ in conjunction, the high hetj TFET exhibits $I_{\mathrm{ON}}=135 \mu \mathrm{A} / \mu \mathrm{m}(350 \%$ enhancement over the homj TFET) at $V_{D S}=0.5 \mathrm{~V}$ and $V_{G S}-V_{\mathrm{OFF}}=$ $1.5 \mathrm{~V}$. This is the highest ever gated interband tunneling 
TABLE I

Benchmarking of the High HeTJ TFET $I_{\text {ON }}$ Against Those EXPERIMENTALly Demonstrated to Date. The High HETJ TFET Shows Not ONLY The Highest $I_{\text {ON }}$ But Also the Highest $I_{\mathrm{ON}} / I_{\mathrm{OFF}}$ AT $I_{\mathrm{ON}}=135 \mu \mathrm{A} / \mu \mathrm{m}, V_{D S}=0.5 \mathrm{~V}$

\begin{tabular}{|c|c|c|c|c|c|c|c|c|}
\hline Reference & $\begin{array}{c}E b_{\text {eff }} \\
(\mathrm{eV})\end{array}$ & $\begin{array}{c}\mathrm{Lg} \\
(\mathrm{nm})\end{array}$ & $\begin{array}{c}\text { Toxe } \\
(\mathrm{nm})\end{array}$ & $\begin{array}{c}\mathrm{V}_{\mathrm{GS}}-\mathrm{V}_{\text {OFf }} \\
(\mathrm{V})\end{array}$ & $\begin{array}{c}\mathrm{V}_{\mathrm{DS}} \\
(\mathrm{V})\end{array}$ & $\begin{array}{c}\mathrm{I}_{\mathrm{ONN}} \\
(\mu \mathrm{A} / \mu \mathrm{m})\end{array}$ & $\mathrm{I}_{\mathrm{ON}} / \mathrm{I}_{\mathrm{OFF}}$ & $\begin{array}{c}\mathrm{SS}_{\text {eff }} \\
(\mathrm{mV} / \mathrm{dec})\end{array}$ \\
\hline $\begin{array}{c}\text { Dewey et. al } \\
\text { IEDM, 2011[2] }\end{array}$ & 0.74 & 100 & 1.1 & 0.9 & 0.3 & 8 & $1.6 \times 10^{3}$ & 140 \\
\hline $\begin{array}{c}\text { Deweyet. al } \\
\text { IEDM,2011[2] }\end{array}$ & 0.58 & 100 & 1.1 & 0.9 & 0.3 & 17 & $3.4 \times 10^{3}$ & 106 \\
\hline $\begin{array}{c}\text { Zhao et. al, } \\
\text { EDL, 2011[11] }\end{array}$ & 0.58 & 100 & 1.2 & 1.5 & 0.5 & 30 & $6 \times 10^{3}$ & 200 \\
\hline $\begin{array}{c}\text { Mohata et. al } \\
\text { IEDM, 2011 [12] }\end{array}$ & 0.25 & 150 & 2.3 & 1.5 & 0.5 & 135 & 10 & 750 \\
\hline $\begin{array}{c}\text { (This work) } \\
\text { Homj }\end{array}$ & 0.58 & 150 & 2.3 & 1.5 & 0.5 & 30 & $6 \times 10^{3}$ & 200 \\
\hline $\begin{array}{c}\text { (This work) } \\
\text { Mod. Hetj }\end{array}$ & 0.31 & 150 & 2 & 1.5 & 0.5 & 78 & $1.5 \times 10^{4}$ & 179 \\
\hline $\begin{array}{c}\text { (This work) } \\
\text { High Hetj }\end{array}$ & 0.25 & 150 & 2 & 1.5 & 0.5 & 135 & $2.7 \times 10^{4}$ & 169 \\
\hline
\end{tabular}

current reported to date at $V_{D S}=0.5 \mathrm{~V}$. Fig. 3(c) plots DIBT, calculated at $I_{D S}=10 \mathrm{nA} / \mu \mathrm{m}$ and $V_{D S}=0.5 \mathrm{~V}$. Due to $\mathrm{Eb}_{\text {eff }}$ and Toxe scaling, DIBT reduces by $65 \%$. DIBT improves with reducing $E b_{\text {eff }}$ due to the interband generation occurring closer to the $\mathrm{S}-\mathrm{C}$ metallurgical interface, thus improving device electrostatics, as shown in Fig. 3(d) [9]. $I_{\mathrm{ON}} / I_{\mathrm{OFF}}$ is another key factor to consider. In this letter, $\mathrm{Eb}_{\text {eff }}$ has been reduced by $57 \%$ and could have been achieved in two ways: 1) by reducing the band gap in the homj TFET or 2) by modifying the stagger using band lineup engineering in the hetj TFET, as shown in this letter. In both cases, $I_{\mathrm{OFF}}$ will be determined by the Shockley-Read-Hall (SRH) generation-dominated leakage of a reversed biased $\mathrm{p}-\mathrm{i}-\mathrm{n}$ diode [10]. In the former case, a change in the homj band gap from 0.58 to $0.25 \mathrm{eV}$ ( $57 \%$ decrease) would lead to an exponential increase in leakage by $\sim 570$ times at room temperature. In the second case, the bulk SRH generation rate is expected to linearly change since the constituent bandgap values stay unchanged and only the built-in field at the tunnel junction changes. This explains why the leakage current changes only by three times and highlights the advantage in employing staggered heterojunctions to enhance drive currents in TFETs while maintaining similar ON-OFF current ratio. The SS in all the fabricated devices is greater than $60 \mathrm{mV} / \mathrm{dec}$ at room temperature due to the presence of high density of interface states $D_{\text {it }}$ at the high- $k /$ channel interface [13] and can be improved by including proper surface passivation and high-temperature anneal process steps. The modest degradation observed in the point $\mathrm{SS}$ with reducing $\mathrm{Eb}_{\mathrm{eff}}$ is due to the factor of 3 increasing in the bulk leakage current [see Fig. 2(b)] and can be mitigated by scaling pillar thickness $T_{\text {body }}$.

Table I benchmarks the measured $I_{\mathrm{ON}}$ of the high hetj TFET against those experimentally demonstrated to date. The hetj TFET exhibits the highest $I_{\mathrm{ON}}=135 \mu \mathrm{A} / \mu \mathrm{m}$ with the highest $I_{\mathrm{ON}} / I_{\mathrm{OFF}}=2.7 \times 10^{4}$ ratio. This demonstration of $I_{\mathrm{ON}}$ exceeding $100 \mu \mathrm{A} / \mu \mathrm{m}$ shows that, fundamentally, it is possible for TFETs to deliver MOSFET-like performance at low $V_{\mathrm{CC}}(\leq 0.5 \mathrm{~V})$. In the fabricated devices, the device geometry has not been significantly scaled ( $T_{\text {body }}=$ $500 \mathrm{~nm}$, Toxe $=2 \mathrm{~nm}$ ), and $I_{D S}$ at $V_{G S}-V_{\mathrm{OFF}}=0.5 \mathrm{~V}$ is only $10 \mu \mathrm{A} / \mu \mathrm{m}$. Thus, the large overdrive voltage of $V_{G S}-$ $V_{\mathrm{OFF}}=1.5 \mathrm{~V}$ is required in order to benchmark the high $I_{\mathrm{ON}}$ demonstrated. Further scaling in device geometry and
$D_{\text {it }}$ will enable demonstration of the high $I_{\mathrm{ON}}$ within $V_{\mathrm{ON}}-$ $V_{\mathrm{OFF}}=0.5 \mathrm{~V}$. Finally, the effective SS, benchmarked as $\mathrm{SS}_{\mathrm{eff}}=\left(V_{\mathrm{TH}}-V_{\mathrm{OFF}}\right) /\left(\log \left(I_{\mathrm{TH}} / I_{\mathrm{OFF}}\right)\right)[14]$ between $V_{\mathrm{OFF}}$ and $V_{\mathrm{TH}}=\left(V_{G S}+V_{\mathrm{OFF}}\right) / 2$, reduces with decreasing $\mathrm{Eb}_{\mathrm{eff}}$ and can be explained in line with the improvement in DIBT.

\section{CONCLUSiON}

$\mathrm{In}_{0.7} \mathrm{Ga}_{0.3} \mathrm{As}$ homj control, $\mathrm{GaAs}_{0.4} \mathrm{Sb}_{0.6} / \mathrm{In}_{0.65} \mathrm{Ga}_{0.35} \mathrm{As}$ moderate-stagger, and $\mathrm{GaAs}_{0.35} \mathrm{Sb}_{0.65} / \mathrm{In}_{0.7} \mathrm{Ga}_{0.3} \mathrm{As}$ highstagger hetj TFETs have been fabricated, and the dependence of $I_{\mathrm{ON}}$ and DIBT (short-channel effect) on effective tunneling barrier height $\mathrm{Eb}_{\text {eff }}$ has been systematically studied. By scaling $\mathrm{Eb}_{\text {eff }}$ from 0.58 to $0.25 \mathrm{eV}, 253 \%$ enhancement in $I_{\mathrm{ON}}$ is demonstrated at $V_{D S}=0.5 \mathrm{~V}$, arising due to increased tunneling efficiency. Furthermore, using Toxe scaling in conjunction with $\mathrm{Eb}_{\text {eff }}$ engineering, a record high $I_{\mathrm{ON}}=135 \mu \mathrm{A} / \mu \mathrm{m}$ (350\% enhancement) along with the highest $I_{\mathrm{ON}} / I_{\mathrm{OFF}}=$ $2.7 \times 10^{4}$ in the category of TFETs is achieved at $V_{D S}=0.5 \mathrm{~V}$ and $V_{G S}-V_{\mathrm{OFF}}=1.5 \mathrm{~V}$. DIBT is shown to reduce by $65 \%$ due to the band-to-band generation occurring closer to the $\mathrm{S}-\mathrm{C}$ interface, thus improving device electrostatics.

\section{REFERENCES}

[1] R. Gandhi, Z. Chen, N. Singh, K. Banerjee, and S. Lee, "Vertical Sinanowire n-type tunneling FETs with low subthreshold swing $(\leq 50 \mathrm{mV} /$ decade) at room temperature," IEEE Electron Device Lett., vol. 32, no. 4, pp. 437-439, Apr. 2011.

[2] G. Dewey, B. Chu-Kung, J. Boardman, J. M. Fastenau, J. Kavalieros, R. Kotlyar, W. K. Liu, D. Lubyshev, M. Metz, N. Mukherjee, P. Oakey, R. Pillarisetty, M. Radosavljevic, H. W. Then, and R. Chau, "Fabrication, characterization, and physics of III-V heterojunction tunneling field effect transistors (H-TFET) for steep sub-threshold swing," in IEDM Tech. Dig., Dec. 2011, pp. 33.6.1-33.6.4.

[3] S. Mookerjea, D. Mohata, R. Krishnan, J. Singh, A. Vallett, A. Ali, T. Mayer, V. Narayanan, D. Schlom, A. Liu, and S. Datta, "Experimental demonstration of $100 \mathrm{~nm}$ channel length $\operatorname{In}_{0.53} \mathrm{Ga}_{0.47}$ As-based vertical inter-band tunnel field effect transistors (TFETs) for ultra low-power logic and SRAM applications," in IEDM Tech. Dig., Dec. 2009, pp. 1-3.

[4] M. Luisier and G. Klimeck, "Performance comparisons of tunneling fieldeffect transistors made of InSb, carbon, and GaSb-InAs broken gap heterostructures," in IEDM Tech. Dig., 2009, pp. 1-4.

[5] Nextnano, Poing, Germany, Nano Device Simulator, 2011

[6] A. Verhulst, B. Soree, D. Leonelli, W. G. Vandenberghe, K. Maex, and G. Groeseneken, "Boosting the on-current of a n-channel nanowire tunnel field-effect transistor by source material optimization," J. Appl. Phys., vol. 104, no. 6, pp. 064514-1-064514-10, Sep. 2008.

[7] D. K. Mohata, R. Bijesh, V. Saripalli, T. Mayer, and S. Datta, "Selfaligned gate nanopillar $\mathrm{In}_{0.53} \mathrm{Ga}_{0.47}$ As vertical tunnel transistor," in Proc. DRC, Jun. 2011, pp. 203-204.

[8] Sentaurus Users Guide, Nextnano, Poing, Germany, Ver. D-2010.03-sp1, 2010.

[9] D. Mohata, S. Mookerjea, A. Agrawal, Y. Li, T. Mayer, V. Narayanan, A. Liu, and S. Datta, "Experimental staggered-source and N+ pocketdoped channel III-V tunnel field-effect transistors and their scalabilities," Appl. Phys. Exp., vol. 4, no. 2, pp. 024105-1-024105-3, Feb. 2011.

[10] S. M. Sze, Physics of Semiconductor Devices. New York: Wiley, 1981.

[11] H. Zhao, Y. Chen, Y. Wang, F. Zhou, F. Xue, and J. Lee, “ $\operatorname{In}_{0.7} \mathrm{Ga}_{0.3} \mathrm{As}$ tunneling field-effect transistors with an ion of $50 \mu \mathrm{A} / \mu \mathrm{m}$ and a subthreshold swing of $86 \mathrm{mV} / \mathrm{dec}$ using $\mathrm{HfO}_{2}$ gate oxide," IEEE Electron Device Lett., vol. 31, no. 12, pp. 1392-1394, Dec. 2010.

[12] D. K. Mohata, R. Bijesh, S. Mujumdar, C. Eaton, R. Engel-Herbert, T. Mayer, V. Narayanan, J. Fastenau, D. Loubychev, A. Liu, and S. Datta, "Demonstration of MOSFET-like on-current performance in arsenide/ antimonide tunnel FETs with staggered hetero-junctions for $300 \mathrm{mV}$ logic applications," in IEDM Tech. Dig., Dec. 2011, pp. 33.5.1-33.5.4.

[13] S. Mookerjea, D. Mohata, T. Mayer, and V. Narayanan, and S. Datta, "Temperature-dependent $I-V$ characteristics of a vertical $\operatorname{In}_{0.53} \mathrm{Ga}_{0.47} \mathrm{As}$ tunnel FET," Electron Device Lett., vol. 31, no. 6, pp. 564-567, Jun. 2010.

[14] A. Seabaugh and Q. Zhang, "Low-voltage tunnel transistors for beyond CMOS logic," Proc. IEEE, vol. 98, no. 12, pp. 2095-2110, Dec. 2010. 